\title{
El ocaso de un rebelde: los últimos años de Ricardo Flores Magón
}

\author{
The Decline of a Rebel: the Final \\ Years of Ricardo Flores Magón
}

\author{
David Flores Magón Guzmán \\ (D) 0000-0001-8333-8469 \\ Universidad de Guanajuato, México \\ magon_guzman@yahoo.com.mx
}

Resumen: Describo la razón por la que se encarceló a Ricardo Flores Magón en 1918, la lucha propresos políticos emprendida por organizaciones, sindicatos y compañeros de Estados Unidos y México para su liberación, el proceso de la enfermedad de Ricardo, sus últimos años de ejercicio epistolar dentro de la cárcel de Leavenworth en Kansas City y el momento catártico que desata la "crisis" entre varios actores políticos, cuando se anuncia su muerte el 21 de noviembre de 1922. La importancia de mi estudio radica en el uso de algunas fuentes de investigación inéditas, el punto de vista en el estudio de la figura de Flores Magón y en el abordaje del tema sobre los acontecimientos que antecedieron la organización de su funeral antes de ser trasladado a la ciudad de México en 1923.

Palabras clave: historia cultural; representación; enfermedad; muerte; Ricardo Flores Magón.

Abstract: I describe the reason why Ricardo Flores Magón was imprisoned in 1918, the struggle for political prisoners undertaken by organizations, unions, and comrades from the United States and Mexico for his release, the process of Ricardo's illness, his last years of letter writing at Leavenworth Prison in Kansas City and the cathartic moment triggering the "crisis" between various political actors, when his death was announced on November 21, 1922. The importance of my study lies in the use of unpublished research sources, the 
point of view of Flores Magón and the analysis of the events leading up to his funeral before he was transferred to Mexico City in 1923.

Key words: cultural history; representation; disease; death; Ricardo Flores Magón.

Fecha de recepción: 16 de febrero de 2017 Fecha de aceptación: 13 de septiembre de 2017

$E_{d}^{s}$ ste artículo expone dos momentos coyunturales que marcan los antecedentes para la realización del funeral de Ricardo Flores Magón de 1923. En primer término, el periodo de 1918 en el cual a Ricardo y a Librado Rivera los acusaron, las autoridades estadunidenses, de sedición porque publicaron un manifiesto antibelicista en el periódico Regeneración. El segundo momento coyuntural se ubica cuando se anuncia la muerte de Ricardo Flores Magón el 21 de noviembre de 1922.

Existen dos ideas fundamentales para entender el proceso del encarcelamiento y muerte de Ricardo Flores Magón. La primera se refiere a la entrada de Flores Magón a la cárcel en 1918, su proceso judicial y su muerte. A estos hechos los caracterizó un discurso antiimperialista contra el gobierno estadunidense, de parte de los movimientos obreros "rojos", radicales o izquierdistas. En este proceso histórico se entrecruza una serie de factores y contextos que refuerzan el espíritu anti "yanqui" de las manifestaciones en torno a la figura de Ricardo Flores Magón.

La segunda consiste en el deficiente estado de salud de Ricardo: padeció diabetes, reumatismo, tuberculosis, cataratas y un estado de ceguera parcial. Las enfermedades se convirtieron en el argumento central que su abogado, amigos y grupos propresos políticos usaron para propugnar la liberación de Ricardo. En el proceso jurídico que duró aproximadamente cinco años, los padecimientos de Ricardo se volvieron públicos y el cuerpo enfermo de Flores Magón se revistió de tintes políticos en contra de las autoridades estadunidenses. 


\section{EL ESPÍRITU ANTIIMPERIALISTA: LOS ENEMIGOS "ROJOS"}

Sitúo el sentimiento antiestadunidense en dos momentos históricos importantes. El primero se refiere al nacimiento del movimiento obrero en México, en 1906, cuando surgieron las primeras huelgas organizadas principalmente contra capitalistas extranjeros, la mayoría de ellos de origen estadunidense; la promulgación de la Constitución mexicana de 1917, y los vínculos binacionales entre los movimientos obreros radicales de Estados Unidos y México. ${ }^{1}$ En el segundo, ubico el antecedente en la política interna y externa que llevó a cabo el gobierno de Estados Unidos durante el periodo de la primera guerra mundial (1914-1918) con la persecución sistemática contra los grupos obreros y radicales por el temor al creciente embate de la "amenaza roja" de los movimientos de izquierda y la revolución rusa.

En este contexto, se da la coyuntura que lleva a Ricardo Flores Magón a la prisión en 1918, tras publicar -junto con Librado Rivera- un supuesto manifiesto antibélico en el que llamaron a abstenerse de tomar las armas a favor del ejército estadunidense por considerar a la primera guerra mundial una "lucha burguesa" que respondía a los intereses de los poderosos y no de la clase trabajadora.

Ricardo Flores Magón era un objetivo clave en la política de represión contra grupos de izquierda. Mantenía filiación con grupos radicales en Estados Unidos. En Los Ángeles, los magonistas recibieron la simpatía y la ayuda financiera de la comunidad socialista, las corrientes anarquistas y de la Industrial Workers of the World (Iww) también conocida como los wobblies. Esta organización también creía en la acción directa y estaba asentada en California, dedicada a agitar a los desempleados y los trabajadores agrícolas. Para estas fechas (1911-1918), Regeneración se había convertido en un periódico internacionalista que permeaba entre las organizaciones obreras estadunidenses:

No sólo cubrió la difícil situación de los mexicanos al sur de la frontera, sino que también tomó la bandera de las comunidades marginadas en Estados Unidos, criticó el racismo generalizado y la satanización de los movimientos de los trabajadores en la prensa dominante de Los Ángeles [...] Esto generó a

${ }^{1}$ Por cuestiones de extensión no abordaré este tema en el presente artículo. 
Regeneración y a Ricardo enemistad con el propietario del Los Angeles Times y gran terrateniente en México, Harrison Gray Otis. El periódico de Los Angeles Times pintó a Ricardo Flores Magón como un villano, como condenaron a todos los movimientos pro-laborales. (Barragan y Bray, 2014)

El crecimiento de los movimientos radicales en Estados Unidos, tanto locales como extranjeros, el contexto de la primera guerra mundial y la revolución bolchevique alertaron al gobierno estadunidense y comenzó una campaña sistemática de persecución contra los "enemigos rojos". Los grupos radicales obreros y los movimientos izquierdistas que se materializaban al interior de Estados Unidos comenzaron a significar una gran amenaza para la política interna del país, sobre todo con los líderes extranjeros.

Tras el ingreso de Estados Unidos a la primera guerra mundial en 1917, la represión contra estos grupos comenzó a realizarse de forma sistemática por parte del gobierno. Estados Unidos vivía una histeria gubernamental en torno a la "peste roja" que provenía del rechazo al socialismo soviético como una forma de gobierno viable tras la revolución bolchevique de 1917.

Cuando Woodrow Wilson llegó a la presidencia de Estados Unidos en 1913, denotó su descontento ante la postura que había tomado el gobierno de Victoriano Huerta frente a su país. Huerta tenía una alianza estratégica con Alemania, que reconocía al "gobierno golpista" de Huerta, convirtiendo a México en uno de los países colaboradores más importantes de América para los germanos. Asimismo, Huerta mencionó públicamente que estaba desarrollando fuertes relaciones con Japón, otro de los enemigos directos de Estados Unidos. A partir de entonces, Wilson decidió ejercer mayor presión contra el gobierno de Huerta y ocupó con fuerzas militares el puerto de Veracruz el 21 de abril de 1914. Victoriano Huerta renunció a la presidencia en julio de 1914 y huyó hacia Europa en el barco de guerra alemán Dresden (Raat, 1988, p. 239).

De la misma forma, fuera de la cúpula gubernamental, el presidente Wilson comenzó una campaña antirradical para defender a Estados Unidos y el mundo de un inminente crecimiento de grupos radicales y de tendencias socialistas, comunistas y anarquistas, caracterizados como antiamericanistas y bolcheviques.

El gobierno de Estados Unidos reaccionó ante la "histeria local" realizando sus propias campañas antirradicales y antiextranjeras, desde 1916 y hasta el periodo de la posguerra (Raat, 1988, p. 242). En 1916 arremetió por 
medio del espionaje y persiguió a los fuerzas magonistas radicadas en Estados Unidos, principalmente contra Ricardo y Enrique Flores Magón, acusándolos de difamar a Venustiano Carranza: "La furibunda petición Ricardo de que se hiciera justicia por los actos ilegales de los rangers texanos, combinada con la posición de Regeneración frente a Carranza y la revolución en México, le dio el pretexto perfecto al gobierno de Estados Unidos para arrestar y enjuiciar a Ricardo y Enrique" (Lomnitz, 2016, p. 599).

En este contexto, arrestaron a Enrique y Ricardo Flores Magón el 18 de febrero de 1916, en su casa de Edendale, California, acusados de violación de la Sección 211 del Código Penal de los Estados Unidos de 1910 ("depositar material indecente en el correo de Estados Unidos”). La acusación se sustentaba en la publicación y envío de los artículos "Los levantamientos en Texas" (30 de octubre de 1915), "A los soldados carrancistas" (6 de noviembre de 1915) y "Las reformas carrancistas" (27 de noviembre de 1915), a través de los números 210, 211 y 214 de Regeneración, respectivamente. El 19 de febrero se les declaró formalmente presos y se les fijó fianza de 5000 dólares a cada uno. ${ }^{2}$

El 7 de marzo de 1916, desde la cárcel del condado de Los Ángeles, California, Ricardo y Enrique Flores Magón escribieron una carta dirigida a los "camaradas", en la que explicaron los detalles violentos de su detención y la presión a la que los sometieron en la cárcel y la incomunicación en que los mantuvieron. Se alegaba la falta de libertad de expresión y se agradecían las muestras de afecto por parte de los compañeros: "Desde el fondo de nuestra mazmorra enviamos nuestros saludos fraternos a nuestros hermanos y camaradas de todas la latitudes, a quienes exhortamos a unirse a nuestro clamor: ¡Viva la libertad de pensamiento! ¡Más energía en la lucha por Tierra y Libertad!"

Los hermanos Flores Magón permanecieron en la cárcel hasta agosto, cuando se pagó la fianza con el dinero que se reunió en un mitin en Los Ángeles, reunión que promovieron Emma Goldman y Alexander Berkman, dos líderes anarquistas de origen ruso, deportados poco tiempo después. ${ }^{3}$

La campaña wilsoniana continúo contra los grupos radicales estadunidenses. El 15 de junio de 1917 se promulgó la Ley de Espionaje. El presidente

${ }^{2}$ Ricardo y Enrique Flores Magón a los “camaradas”, 7 de marzo de 1916. Las notas son de Jacinto Barrera Bassols. Archivo electrónico Ricardo Flores Magón [en línea]. Recuperado de http://www.archivomagon.net/ObrasCompletas/Correspondencia/Cor356

${ }_{3}^{3}$ Ricardo y Enrique Flores Magón a los "camaradas”, 7 de marzo de 1916. Archivo electrónico Ricardo Flores Magón [en línea]. Recuperado de http://www.archivomagon.net/ ObrasCompletas/Correspondencia/Cor356 
Wilson ordenó - desde el Departamento de Guerra- reprimir cualquier intento de reunión, manifestación y exaltación del ideal "rojo". Se allanaron las instalaciones de la IWW, y se persiguió a varios movimientos obreros. El ejército invadió las salas de reunión de esta organización, arrestó a los organizadores, rompió varias huelgas, ejerció espionaje sobre el correo y encarceló ilegalmente a cientos de "radicales" nacionales y extranjeros a lo largo de todo el país (Raat, 1988, pp. 242-243). Se radicalizó la represión en Estados Unidos contra la prensa independiente y, en particular, contra los periódicos anarquistas. A centenares de revolucionarios los arrestaron y condenaron a largas penas por delitos de propaganda contra la guerra (Bartra, 1991, p. 53), especialmente a los extranjeros se les impusieron condenas más severas, como lo señala Romero (2008):

Incluso más que la vieja Europa, Estados Unidos vivió días de histeria. Su Presidente Woodrow Wilson extendió su apoyo a las iniciativas de su fiscal general, Alexander Mitchell Palmer, que veía comunistas detrás de cada arbusto. En un auténtico precedente a la caza de brujas del senador Joseph McCarthy en los años cincuenta, Palmer reclutó a un entonces muy joven John Edgar Hoover [primer director del FBI] como ayudante al frente de la División General de Inteligencia [General Intelligence Division] cuyo objetivo era el del descubrir los "complots Bolcheviques" [...] durante las llamadas "Redadas Palmer" [Palmer Raids], organizaciones izquierdistas y sindicatos obreros fueron infiltrados, miles de sospechosos fichados y muchos de ellos encarcelados sin juicio, unos 10000 residentes extranjeros arrestados y cientos de ellos deportados (p. 3).

En este mismo contexto de persecución, se dieron cientos de casos similares por todo el país. El 12 julio de 1918, a María Talavera Brousse, esposa de Ricardo Flores Magón, la arrestaron junto con Epigmenio Zavala; el juez de Los Ángeles, Benjamin F. Bledsoe los acusó de violar el acta de espionaje. ${ }^{4}$ Después de cinco meses de encarcelamiento, los liberaron sin procesarlos.

${ }^{4}$ Ricardo Flores Magón a Raúl Palma, 6 de agosto de 1918. Archivo electrónico Ricardo Flores Magón [en línea]. Recuperado de http://www.archivomagon.net/ObrasCompletas/ Correspondencia/Cor361 El acta de espionaje se refiere a la Ley Federal de Espionaje promulgada en Estados Unidos en 1917 durante la primera guerra mundial. Buscaba evitar de forma general, la interferencia y fuga de información en operaciones militares. Aplicaba para militares, ciudadanos estadunidenses y extranjeros radicados en ese país. Dicha ley de espionaje sigue vigente. 
En 1918 detuvieron a Ricardo Flores Magón y a Librado Rivera debido a la publicación de un manifiesto antibelicista en el número 262 del periódico Regeneración, que apareció el 16 de marzo de 1918 en Los Ángeles, California. El texto estaba dirigido a los miembros de la Junta Organizadora del Partido Liberal Mexicano, a los miembros del partido, a los anarquistas de todo el mundo y a los trabajadores en general. Paradójicamente este sería el último número que publicaría Regeneración.

El manifiesto planteaba la muerte de la "vieja sociedad burguesa" que agonizaba para dar paso a una nueva era histórica. Discutía acerca de la conciencia de los trabajadores y desprotegidos sobre las condiciones de explotación en las que se encontraban "Las flamas del descontento se avivan al soplo de la tiranía", el momento de "la insurrección de todos los pueblos contra las condiciones existentes". El manifiesto insiste en la razón del revolucionario y el débil para sublevarse, para preparar el momento que se avecinaba. Llama a los que no creen en el gobierno a que propaguen el ideal anarquista. ${ }^{5}$

Por este motivo, en 1918 el gobierno estadunidense culpó a Ricardo Flores Magón y a Librado Rivera de sedición. Los denunció por violar la Ley de Espionaje y los acusó de conspirar por escribir y publicar declaraciones falsas encaminadas a interferir con el funcionamiento militar de Estados Unidos. ${ }^{6}$ Se les imputó también que sus declaraciones incitaban a la insubordinación y la deslealtad de las fuerzas militares (Raat, 1988, p. 261).

Dentro del Departamento de Justicia de Estados Unidos se clasificó el caso de Ricardo Flores Magón y Librado Rivera como un problema de seguridad interna en dos niveles: como anarquista dedicado a la destrucción del Estado y como influencia negativa para los mexicanos de ambos lados del río Bravo (Bartra, 1991, p. 202). Se les acusó de tratar de intervenir en los planes del gobierno de Estados Unidos por su entrada a la primera guerra mundial, $y$ de formar un discurso antibelicista y en contra del gobierno. Los sentenciaron a 20 y 15 años de prisión, respectivamente.

En este contexto, a Ricardo Flores Magón y Librado Rivera se les consideró enemigos del Estado por sus ideales. El gobierno de Estados Unidos

\footnotetext{
${ }_{5}^{5}$ Para conocer el texto en extenso consúltese en http://archivomagon.net/periodicos/ regeneracion-1900-1918/4ta-epoca/e4n262

${ }^{6}$ Específicamente se les acusó de violar la sección 3 del título I, y la sección 3 del título XII, el decreto del 6 de octubre de 1917 que prohibía hacer tratos con el enemigo (sección 19), y la sección 211 del Código Penal Federal de 1910. Nota de Jacinto Barrera Bassols. Recuperado de http://www.archivomagon.net/
} 
se centró en la penalización del discurso, y no sobre una conducta o una acción concreta. Esto responde a un sistema de "justicia" occidental, donde el pensamiento, el saber y disertación son castigados. Para tal efecto, la justicia estadunidense aplicó una sentencia de 20 años de cárcel para Flores Magón, no como una condena individual, sino como una condena pública, colectiva, que representara un castigo ejemplar para todos aquellos simpatizantes que expresaran sus ideas contra la política de Estados Unidos.

Al momento de la sentencia en 1918, a Ricardo Flores Magón y a Librado Rivera se les transportó a la prisión del condado de Los Ángeles. Posteriormente los reubicaron -el 15 de agosto de 1918- en la prisión McNeil Island en Washington; ahí los obligaron a realizar trabajos forzados. Ricardo permaneció en la cárcel de McNeil poco más de un año. Sus enfermedades (diabetes, ceguera, cataratas, reumatismo) lo obligaron a pedir un cambio de prisión. El 3 de noviembre de 1919, lo trasladaron a la penitenciaría de Leavenworth en el estado de Kansas, donde se convirtió en el prisionero 14596L. ${ }^{7}$ A partir de entonces Ricardo permanecería en la prisión hasta su muerte en la madrugada del 21 de noviembre 1922.

\section{CAUTIVERIO, PROCESO JURÍDICO Y ENFERMEDAD DEL PRISIONERO 14596-L}

Ricardo Flores Magón permaneció en la prisión federal de Leavenworth los últimos cinco años de su vida (1918-1922), purgando una condena de 20 años por supuestos actos de sedición contra el gobierno estadunidense. Estos años constituyen una base fundamental para entender su pensamiento y filosofía política radical al final de su vida. Durante ese tiempo enfrentó un proceso judicial para poder obtener su liberación, se argumentó que las enfermedades que padecía le imposibilitaban seguir una vida estable dentro de la prisión.

Tanto su abogado Harry Weinberger ${ }^{8}$ como grupos organizados en pro de los presos políticos, buscaron la libertad de Flores Magón a través de la

\footnotetext{
${ }^{7}$ Esta prisión fue la cárcel más grande de máxima seguridad en Estados Unidos hasta 2005.

${ }^{8}$ Defensor de personajes como Emma Goldman y Alexander Berkman, durante y después de la primera guerra mundial, y consejero legal de la Liga para la Amnistía de los Presos Políticos (League for the Amnesty of Political Prisoners); fue contratado en 1919 por el Comité de Defensa y Alivio de Presos Políticos (Political Prisoners Defense \& Relif Committe), con
} 
vía legal: realizaron manifestaciones, recaudaron fondos y enviaron constantemente telegramas al procurador general de Justicia Harry M. Daugherty y a los presidentes de Estados Unidos Thomas Woodrow Wilson (1913-1921) y Warren G. Harding (1921-1923) para exigir la liberación de Flores Magón. ${ }^{9}$

La defensa legal para liberar a Ricardo Flores Magón se basó en el argumento de su mala salud, pérdida de la vista y la negativa de arrepentimiento acerca de su ideal radical. El "cuerpo enfermo" se convirtió en un asunto de interés público y político, hasta transformarse en la bandera principal que su abogado Weinberger y las organizaciones propresos políticos ondearon, para gestionar su libertad parcial. El objetivo era lograr que lo revisara un médico externo al de la cárcel, o negociar su libertad definitiva para deportarlo a México. Por su parte, el alcaide de la penitenciaría de Leavenworth, W. I. Biddle, informaba constantemente al procurador Daugherty que, según el médico de la prisión, el estado de salud de Flores Magón era perfectamente estable. Se sabe, sin embargo, que las enfermedades de Ricardo ya eran evidentes desde su encarcelamiento en 1916 cuando fue encerrado junto con su hermano Enrique: "se había encontrado dos veces en el umbral de la muerte y estaba tan enfermo cuando los juzgaron y declararon culpable en junio de 1916 que no pudo hablar en la corte [...] Igualmente preocupante en Ricardo era la pérdida de la vista, un problema que atribuían a las largas horas nocturnas en que tenían que trabajar casi siempre con mala luz" (Lomnitz, 2016, p. 604). El tema de las enfermedades de Ricardo estuvo en el centro del proceso judicial y se incluyó en la polémica de su muerte. Las vías legales fueron infructuosas para liberar a Flores Magón de su condena de 20 años en prisión.

El proceso judicial no se atendió o discutió en el Departamento de Justicia, pues Ricardo estuvo en prisión bajo la etiqueta de preso político. En este complicado proceso, la justicia estadunidense se encontraba en una cruzada contra los "movimientos rojos" especialmente liderados por extranjeros. Aunado a esto, Ricardo se negó a firmar una carta de arrepentimiento por

sede en Nueva York, para la defensa de los llamados mártires de Texas, José M. Rangel y Charles Cline.

${ }^{9}$ Fue uno de los principales financiadores de la campaña del presidente Warren G. Harding, ocupó el cargo de procurador general de Estados Unidos en marzo de 1921. El equipo cercano de colaboradores de Harding, donde se encontraba Harry M. Daugherty como uno de los principales líderes, se les conocía como "Ohio Gang" (la pandilla de Ohio) por supuestos escándalos financieros y actos ilícitos fiscales, incluyendo el Departamento de Justicia a cargo de Daugherty. 
profesar ideales revolucionarios, rectificación que la Procuraduría General de Justicia le exigía para liberarlo. Su carácter de preso político inmigrante y su negativa a retractarse lo condenaron a permanecer preso a pesar de su estado físico enfermizo.

A partir de esto, podemos entender cómo Estados Unidos construía a sus "enemigos", así como el proceso político que vivió Ricardo Flores Magón frente a la ley estadunidense, sus condiciones anímicas y de salud, y su postura final en sus últimos años como luchador cautivo. Los discursos que se generaron a partir del caso enfermizo de Flores Magón en estos últimos años, surgen de dos fuentes de información principales: los periódicos de la época, de tendencia radical, y el ejercicio epistolar que mantuvo Ricardo con diferentes actores sociales.

Estos discursos incurren en la relación de lo público y lo privado, lo personal y lo político: los aspectos personales bajo una lectura política se entremezclan en este corpus de correspondencia homogénea que procede del mismo lugar en la misma coyuntura, donde se puede entender cómo se está percibiendo Flores Magón a sí mismo y cómo lo están percibiendo en el exterior desde lo colectivo.

Su correspondencia de 1918 a 1922 muestra a un Ricardo Flores Magón sensible, alejado de los discursos combativos que lo caracterizaron a lo largo de su vida. Revela un discurso maduro, generoso, contundente y esperanzador. En sus cartas, Ricardo menciona constantemente los conceptos de paz, amor, felicidad y humanidad solidaria. Insiste en el cumplimiento del ideal anarquista, como el sendero utópico por el cual la humanidad tiene que caminar para llegar al bienestar social. Otra mención recurrente dentro de su correspondencia fue su vulnerable condición física y el sufrimiento que le ocasionaron sus padecimientos.

A lo largo de estos cinco años en prisión, Ricardo recibió 716 cartas y envío 435. De las primeras sólo se han localizado 23, mientras que de las emitidas por Ricardo se han encontrado 117. Por ser considerado un "prisionero de primera" dentro del reglamento de la cárcel de Leavenworth, sólo se le otorgaba el derecho de escribir tres cartas personales por semana, de dos hojas cada una, y un número indeterminado, a discreción de la autoridad, cuando estuvieran dirigidas a las autoridades o a sus abogados (Barrera, 2001, p. 11).

Ricardo tenía una especial afición por escribir y recibir cartas de sus compañeros, sobre todo cuando se encontraba encarcelado. La correspon- 
dencia y los acontecimientos que se suscitaron permiten delinear el contexto para entender la última etapa de la postura radicalizada, humanista y utópica de Ricardo Flores Magón. La narrativa de Ricardo se va construyendo a partir de sus condiciones físicas, anímicas y legales, lo que va moldeando su figura de "mártir" o "héroe popular" que será reforzada tras su muerte en las honras fúnebres que se le tributaron.

\section{PROCESO JUDICIAL Y ENFERMEDADES DE RICARDO FLORES MAGÓN}

Recordemos que a Ricardo Flores Magón y Librado Rivera los aprendieron el 22 de marzo de 1918, por publicar el manifiesto antibelicista, enviándolos inmediatamente a la prisión del condado de Los Ángeles. Cinco meses después, los transfirieron a la penitenciaría federal McNeil Island, en Washington, el 15 de agosto de 1918. Cuando les notificaron el traslado, Ricardo Flores Magón escribió una carta dirigida a Raúl Palma en la que se nota a un Ricardo animado, y donde reafirma su convicción anarquista y se autorrepresenta como un mártir de los trabajadores:

Yo marcho contento a sufrir el castigo, porque mi martirio es una parte de la fuerza que ha de derribar el edificio que nos oprime a todos. En mi calabozo, con las manos atadas y reducido al parecer a la impotencia, mi sola presencia dentro de las cuatro duras paredes de mi encierro, constituye una fuerza que día a día trabaja en las mentes de los que me aman y simpatizan con mi larga y penosa labor [...] Ves, pues, mi querido Raúl, que aunque al parecer impotente, el prisionero es fuerte, con la fuerza que cría el dolor. ${ }^{10}$

Tras permanecer ahí poco más de un año, Ricardo solicitó cambiar de prisión debido a las condiciones climáticas húmedas de McNeil, que afectaban su estado de salud. Recordemos que Flores Magón fue transferido a la prisión federal Leavenworth en el estado de Kansas en noviembre de 1919. Su estado enfermizo y falto de ánimo se hacía notar meses después a través de la

${ }^{10}$ Ricardo Flores Magón a Raúl Palma, 6 de agosto de 1918. Archivo electrónico Ricardo Flores Magón [en línea]. Recuperado de http://www.archivomagon.net/ObrasCompletas/ Correspondencia/Cor361 
correspondencia de Ricardo Flores Magón. Mencionó de forma "privada" sus enfermedades en una carta que dirigió a Gus Teltsch, ${ }^{11}$ fechada el 1 de marzo de 1920. Ricardo le mencionó los inicios de sus aflicciones: "Cuando recibí tu carta del 15, estaba yo en el hospital de esta institución sufriendo de un ataque de influenza y pulmonía. Sin embargo, fui atendido bien y prontamente. Por supuesto que me siento muy débil; pero la primavera entrante me ayudará a la completa restauración de mi salud."12 Según los registros del Departamento de Justicia de Estados Unidos dentro de los National Archivies - recuperados por Lomnitz-se puede conocer toda una serie de pequeñas prácticas cotidianas que llevaba a cabo Ricardo Flores Magón durante su encierro en Leavenworth ligados a su alimentación, aficiones y su estado de salud:

Entre el 1 de junio de 1919 y el 30 de junio de 1920, hubo siete días en que Ricardo no trabajó. Sabemos cuándo y cuánto tabaco, fósforos y papel para cigarros compró. Podemos ver que de vez en cuando compraba fruta: uvas, manzanas, pasas, nueces. Ocasionalmente, un lápiz, también. Con permiso especial, se hizo tomar una foto para mandársela a su familia. Recibió una revista y dos libros como regalos [...] Sabemos las cifras de su crédito en la cárcel [...] Sabemos que en los dos años que van de su llegada a Leavenworth, el 3 de noviembre de 1919, y su muerte, Ricardo se sintió lo suficientemente enfermo para ver a un doctor en veintidós ocasiones y que vio a un dentista catorce veces (Lomnitz, 2016, p. 626).

Aun sin utilizar el argumento de los padecimientos físicos de Flores Magón, manifestaciones de organizaciones obreras exigían la liberación de Ricardo. El procurador Daugherty le negó la libertad por considerar que Flores Magón era una amenaza para Estados Unidos y para México. En una publicación fechada el 8 de octubre de 1919, recordaba que Ricardo "se había convertido en la cabeza principal de los agitadores que buscaban introducir el bolchevismo en Estados Unidos" (Hernández, 1994, p. 202). Casi un año después, el 5 de febrero de 1920, nuevamente se iniciaron gestiones para libe-

${ }^{11}$ Anarquista austriaco que estuvo encarcelado junto con Flores Magón en la penitenciaria federal de McNeil Island.

${ }^{12}$ Carta dirigida a Gus Teltsch de Ricardo Flores Magón. 1 de marzo de 1920. Obras completas. Correspondencia 1899-1922. Archivo electrónico Ricardo Flores Magón [en línea]. Recuprado de http://archivomagon.net/obras-completas/correspondencia-1899-1922/c-1920/ cor04-2 
rar a Ricardo Flores Magón. Sus "camaradas" que se encontraban en libertad comenzaron a buscar los mecanismos necesarios para gestionar la salida de la cárcel, por considerar que su prisión tenía que ver directamente con cuestiones de persecución política y no legales. En un principio los camaradas pidieron el apoyo de la International Worker's Defense League (IWDL), la cual se negó a apelar la sentencia por considerar los procesos de Flores Magón y Rivera casos irresolubles.

A partir de entonces, el proceso judicial de Ricardo Flores Magón se complejizó y podía adivinarse la negativa del gobierno estadunidense, representado por el procurador general de Justicia Harry M. Daugherty, porque Ricardo obtuviera su libertad sin cumplir los 20 años de condena. Sin embargo, según relata Ricardo Flores Magón en su correspondencia, sus enfermedades comenzaban a ser un gran problema que se acrecentaba día a día. Representaban la imposibilidad para que Flores Magón cumpliera su condena en cautiverio. En esta carta enviada nuevamente a Gus Teltsch, fechada en mayo de 1920, Ricardo comentó sobre el glaucoma y las cataratas que lo aquejaban, y que le causarían una ceguera definitiva:

Estoy avergonzado de no haber contestado más pronto tu amable carta del 9 de abril último; pero esto ha sido a causa de mi mala salud. Estuve muy enfermo durante todo el mes de abril y la última parte de marzo, y para coronar mi desgracia me estoy quedando ciego. Me siento mejor ahora, con excepción de la vista, que se me está poniendo más débil cada día. Estoy condenado a cegar, querido camarada; estoy condenado a ser un objeto cualquiera. El oculista de esta institución se ha tomado muchas molestias para tratar de encontrarme anteojos apropiados; pero sus esfuerzos han sido en vano. Mis ojos ya están demasiado dañados. Por lo tanto, estoy en espera de la eterna obscuridad que va a envolverme mientras viva [...] Para mí, el no ver es una positiva desgracia. ¡No ver más la luz ...! ¿ ¿Has pensado tú alguna vez en esto, querido camarada? La sola idea hace que a uno se le revuelva la cabeza. La gente compara la ceguera con la noche. Sí, es la noche; pero sin el encanto de las estrellas. Es la noche, pero sin la poesía de la naturaleza vista a través de la obscuridad. ${ }^{13}$

${ }^{13}$ Ricardo Flores Magón a Gus Teltsch, 4 de mayo de 1920. Archivo electrónico Ricardo Flores Magón [en línea]. Recuperado de http://archivomagon.net/obras-completas/ correspondencia-1899-1922/c-1920/cor06-2 
Con este diagnóstico y con la posibilidad de quedar ciego, Ricardo Flores Magón gestionó un permiso para que lo examinara un médico especialista externo a la prisión. A sugerencia de su amiga Rose Bernstein, alias Erma Barsky, obtuvo el contacto con el abogado neoyorquino Harry Weinberger, especializado en la defensa de presos políticos anarquistas y radicales en Estados Unidos, para tramitar dicho permiso. A lo largo de dos años, Weinberger se convertiría en el encargado de negociar la atención médica y la liberación de Ricardo de la penitenciaría de Leavenworth. Ricardo Flores Magón escribió una misiva el 20 de julio de 1920 al abogado Harry Weinberger para solicitarle su apoyo legal para obtener el permiso para que lo atendiera un especialista:

Mi querida camarada Erma Barsky me pide que le escriba a usted todo lo relativo a la enfermedad de los ojos que padezco. Así lo hago. Cuando mi vista comenzó a debilitarse, al grado de que, en la actualidad, todo lo veo como a través de una niebla, fui a ver al médico encargado del departamento de oftalmología de esta institución. Él examinó mis ojos e intentó encontrar lentes para mí, pero con ninguno pude ver. Diagnosticó que yo padecía de glauco$\mathrm{ma}$, una enfermedad que consiste en el endurecimiento del globo ocular, y me indicó que regresara al cabo de cierto tiempo para examinar mis ojos de nuevo. Volví a presentarme el mes pasado y, entonces, después de examinar nuevamente mis ojos, el doctor diagnosticó cataratas y me hizo saber que prácticamente quedaré ciego en un plazo de seis meses o, tal vez, de un año o algo así [...] La Srita. Barsky me pregunta si podría ser tratado por un especialista externo. Esto contravendría las normas que rigen esta institución, y me parece que el Departamento de Justicia es la única autoridad que podría autorizar ese privilegio. ¿Sería posible que se me permitiera salir de la cárcel para atender mi enfermedad y ser internado de nuevo en cuanto esté curado? Doy mi palabra de que no escaparé, sino que regresaré a la cárcel para purgar mi condena, o parte de ella, porque no creo que viviré lo suficiente para pagar mi deuda a la justicia burguesa. ${ }^{14}$

Así, esta carta del 20 de julio de 1920 inauguró el inicio de la divulgación de los padecimientos de Ricardo. El 26 de julio de 1920, el señor Harry Wein-

${ }^{14}$ Ricardo Flores Magón a Harry Weinberger, 20 de julio de 1920. Archivo electrónico Ricardo Flores Magón [en línea]. Recuperado de http://archivomagon.net/obras-completas/ correspondencia-1899-1922/c-1920/cor07-2 
berger contestó la carta de Ricardo, le aseguró que haría lo posible para que fuera atendido de su enfermedad, solicitando directamente al Departamento de Justicia un permiso especial para ver un médico externo; además de que lo animó a que solicitara personalmente una amnistía para su caso específico ${ }^{15}$

Posteriormente, el 30 de julio de 1920 Weinberger escribió a Ricardo Flores Magón para informarle de sus gestiones en Washington con el asistente del superintendente de prisiones de los Estados Unidos, el señor McGlassen, referentes a la visita de un médico externo en la cárcel, o a su posible salida para que lo atendiera un especialista de Kansas. En la carta también menciona que el propio señor Dickerson, superintendente de prisiones, le escribió una nota donde mencionó lo siguiente: "Si Magón requiere un tratamiento o una operación de sus ojos y el personal médico del penal no puede proporcionárselos, indudablemente se podría tramitar que lo atienda un especialista externo o trasladarlo a un hospital si es preciso operarlo." ${ }^{16}$ En la misma carta que le escribió Harry Weinberger a Flores Magón, le mencionó que era necesario que le enviaran todos los documentos referentes a su detención, declaración y juicios, anexando una declaración propia con sus datos y características principales, y una "declaración de hechos y cargos". ${ }^{17}$

Seis días después de esta carta, Ricardo Flores Magón le contestó al abogado con un extenso escrito, describió su proceso de encarcelamiento, su estado físico, y las razones por las que lo sentenciaron a 20 años de prisión. Enfatizó su opinión acerca de la primera guerra mundial y los mensajes intrínsecos del manifiesto de 1918 por el que se le acusó de delito. La carta revela aspectos fundamentales como la amplitud de su pensamiento político internacionalista, la función pedagógica de su labor como pensador, la reafirmación de su estado de salud deficiente y la negativa de cualquier tipo de arrepentimiento por su labor social. Ricardo además explicó su actividad política referente al manifiesto de 1918, donde argumenta que nunca nombró al gobierno de Estados Unidos, que sólo se refería a las condiciones del mundo

${ }^{15}$ Harry Weinberger a Ricardo Flores Magón, 26 de julio de 1920. Archivo en línea Ricardo Flores Magón [en línea]. Recuperado de http://archivomagon.net/obras-completas/ correspondencia-1899-1922/c-1920/cor08-2

${ }^{16}$ Harry Weinberger a Ricardo Flores Magón, 30 de julio de 1920. Archivo electrónico Ricardo Flores Magón [en línea]. Recuperado de http://archivomagon.net/obras-completas/ correspondencia-1899-1922/c-1920/cor09-2

${ }^{17}$ Harry Weinberger a Ricardo Flores Magón, 30 de julio de 1920. Archivo electrónico Ricardo Flores Magón [en línea]. Recuperado de http://archivomagon.net/obras-completas/ correspondencia-1899-1922/c-1920/cor09-2 
en general, sin mencionar a ningún país en particular. Continuó argumentando sobre su sentencia, la noción de pedir perdón y sobre las injusticias del sistema penal estadunidense. ${ }^{18}$

En noviembre de 1920, el proceso judicial y el deteriorado estado físico de Ricardo Flores Magón ya eran de orden público; las cartas de Flores Magón son reiterativas. En su correspondencia es constante el tema acerca de su estado de salud decadente y la esperanza que tenía de que lo revisara un médico externo a la prisión.

Dentro de este contexto de presión legal y social, aunado a la amnistía general sobre los prisioneros políticos que varios grupos preparaban para la navidad de 1920, el 6 de diciembre de ese año, el Departamento de Justicia le propuso a Ricardo Flores Magón liberarlo con la condición de que firmara una petición de perdón y arrepentimiento de sus ideales. Como ya había anticipado, Flores Magón se negó rotundamente a pedir perdón. En una serie de cartas dirigidas a Nicolás T. Bernal, Ellen White y Gus Teltsch, Ricardo reforzó sus ideales negándose tajantemente a arrepentirse; por el contrario, reafirmó su ideal como luchador social y sostuvo una actitud rebelde frente al gobierno:

En el Departamento de Justicia se dijo al Sr. Weinberger que nada puede hacerse en mi favor si no hago una solicitud de perdón [...] Esto sella mi destino; cegaré, me pudriré y moriré dentro de estas horrendas paredes que me separan del resto del mundo, porque no voy a pedir perdón. ¡No lo haré! En mis veintinueve años de luchar por la libertad lo he perdido todo, y toda oportunidad para hacerme rico y famoso; he consumido muchos años de mi vida en las prisiones; he experimentado el sendero del vagabundo y del paria; me he visto desfalleciendo de hambre; mi vida ha estado en peligro muchas veces; he perdido mi salud; en fin, he perdido todo, menos una cosa, una sola cosa que fomento, mimo y conservo casi con celos fanáticos, y esa cosa es mi honra como luchador. ${ }^{19}$

${ }^{18}$ Ricardo Flores Magón a Harry Weinberger, 5 de agosto de 1920. Archivo electrónico Ricardo Flores Magón [en línea]. Recuperado de http://archivomagon.net/obras-completas/ correspondencia-1899-1922/c-1920/cor10-2

${ }_{19}$ Ricardo Flores Magón a Nicolás T. Bernal, 6 de diciembre de 1920. Archivo electrónico Ricardo Flores Magón [en línea]. Recuperado de http://archivomagon.net/obras-completas/ correspondencia-1899-1922/c-1920/cor18-2 
Es un documento fundamental que revela la postura y autorrepresentación de Ricardo sobre su persona, y que además forma parte del debate central que la figura pública de Flores Magón genera ante los distintos espacios y actores que lo apoyan o lo rechazan por completo. Ricardo entendía perfectamente que su legado trascendería a través de su pensamiento político y sus ideales. Por lo mismo, no podía traicionarlos a ningún costo. Flores Magón agregó que no pediría perdón porque eso significaría traicionar a los trabajadores y a sí mismo. También reafirma una de las características centrales del héroe que se refiere al móvil ético de su acción a favor de la solidaridad y la justicia social:

Pedir perdón significaría que abdico de mis ideales anarquistas; y no me retracto, afirmo, que si la especie humana llega alguna vez a gozar de verdadera fraternidad y libertad, y justicia social, deberá ser por medio del anarquismo. Así pues, mi querido Nicolás, estoy condenado a cegar y morir en la prisión; mas prefiero esto que volver la espalda a los trabajadores, $y$ tener las puertas de la prisión abiertas a precio de mi vergüenza. No sobreviviré a mi cautiverio, pues ya estoy viejo; pero cuando muera, mis amigos quizá inscriban en mi tumba: "Aquí yace un soñador", y mis enemigos: "Aquí yace un loco". Pero no habrá nadie que se atreva a estampar esta inscripción: "Aquí yace un cobarde y traidor a sus ideas". ${ }^{20}$

Las organizaciones de defensa de derechos políticos y civiles estadunidenses, requerían una amnistía general con motivo del fin de año y la conclusión de la primera guerra mundial casi dos años atrás. Los movimientos propresos políticos comenzaban a realizar gestiones y presión sobre el gobierno estadunidense con la esperanza de liberar a una gran mayoría de ellos. Sin embargo, Estados Unidos se mantuvo firme respecto a su temor al movimiento "rojo". Ricardo se enteró por medio de su amiga Ellen White que el movimiento puso especial atención a su caso debido a sus condiciones de salud.

La situación en la que se encontraba Flores Magón, y la negativa casi definitiva de su liberación, provocó que, en diciembre de 1920, el diputado

${ }^{20}$ Ricardo Flores Magón a Nicolás T. Bernal, 6 de diciembre de 1920. Archivo electrónico Ricardo Flores Magón [en línea]. Recuperado de http://archivomagon.net/obras-completas/ correspondencia-1899-1922/c-1920/cor18-2 
Antonio Díaz Soto y $\mathrm{Gama}^{21}$-quien durante un tiempo fue miembro activo del Partido Liberal Mexicano y quien pronunciara el discurso oficial desde la Cámara de Diputados en 1922 a la muerte de Flores Magón- solicitara a la Cámara de Diputados, para que a través del gobierno mexicano se ofreciera una pensión vitalicia a Ricardo Flores Magón, para que solventara sus gastos de manutención y enfermedades. Ricardo rechazó el ofrecimiento, decisión coherente con su base ideológica. Contestó en los siguientes términos: "Soy anarquista, y no podría sin remordimiento y vergüenza, recibir el dinero arrebatado al pueblo por el Gobierno [...] Yo no creo en el Estado; sostengo la abolición de las fronteras internacionales; lucho por la fraternidad universal del hombre; considero el Estado como una institución creada por el capitalismo para garantizar la explotación y subyugación de las masas."22

Posterior a este rechazo, la lucha por la liberación de Flores Magón tuvo un año de aparente calma. Sin embargo, en 1922 la actividad pública se reanimó con mucha fuerza. Estos movimientos sociales inquietaban a los gobiernos de México y Estados Unidos. Los radicales publicaron artículos para informar al público la difícil situación de los presos mexicanos, y continuaron escribiendo apelaciones al procurador general y al presidente Harding (Raat, 1988, p. 268). Organizaciones de México y Estados Unidos pugnaron fuertemente por la liberación de los presos políticos.

Desde México, la Confederación General de Trabajadores, de tendencia anarcosindicalista, realizó varias manifestaciones frente al consulado estadunidense mostrando un discurso antiimperialista. De igual forma la CGT trató de obtener, por intermediación del presidente Álvaro Obregón, la libertad de sus compañeros presos. Pero Obregón envió telegramas a los obreros en los que lamentó no poder obsequiar sus deseos porque las relaciones diplomáticas entre México y Estados Unidos estaban interrumpidas, "no puede oficialmente el gobierno que me honro en presidir dirigirse a la cancillería de la Casa Blanca" (Hernández, 1994, p. 203). Estos grupos de presión intentaron liberar a la mayor cantidad de presos políticos con el fin de que fueran "exhortados" de su cargo y, en el caso de los extranjeros, deportados a

${ }^{21}$ Excompañero de Flores Magón que, siendo diputado, ofrecería una pensión a Ricardo para su manutención en 1920 e incitaría a la Cámara de Diputados por parte del Estado a traer los restos de Flores Magón a México en 1922.

${ }^{22}$ Ricardo Flores Magón a Nicolás T. Bernal, 20 de diciembre de 1920. Archivo electrónico Ricardo Flores Magón [en línea]. Recuperado de http://archivomagon.net/ obras-completas/correspondencia-1899-1922/c-1920/cor24-2 
su país de origen. Debido a que las relaciones diplomáticas entre ambos países estaban rotas, la comunicación diplomática quedaba descartada. Por el contrario, organizaciones obreras de ambos países mantenían un vínculo de comunicación directo, y en ocasiones realizaron actos conjuntos. La figura de Ricardo Flores Magón era de interés binacional. La precaria situación de salud de Ricardo lo colocó como un preso político, un mártir, cuya causa era prioritaria para los gestores políticos.

Con este propósito, el 26 abril de 1922, el Comité Pro Presos Políticos elaboró una tarjeta postal en la que resaltó la postura ideológica de Ricardo Flores Magón y lo presentó como un luchador incansable. La postal nació como un medio para concientizar a los trabajadores y animarlos a ejercer una presión multitudinaria a favor de Ricardo. El texto que acompañó la postal dio cuenta del sufrimiento de Ricardo en la penitenciaría de Leavenworth, "donde a pesar de sufrir el rigor deslumbrador de la libertad yanqui", sigue firme en sus ideales. La postal muestra en la parte frontal una fotografía de Flores Magón, tomada de varios años atrás en su imprenta de Los Ángeles, donde se le observa saludable y como a un hombre de ideas, crítico, trabajador.

Al lado de la imagen se encuentra un texto en el que se informa de la enfermedad y de la injusticia que sufre, y se resalta la firmeza de su pensamiento. La parte posterior de la postal incluye el fragmento de una carta de Ricardo Flores Magón escrita desde la cárcel el 26 de abril de 1922. En pocas, y en sus propias palabras, Ricardo se presentó como un hombre enfermo que vivía en los márgenes de la política. Asumió que su vida no sería muy longeva, "es ya sólo una vela mezquina próxima a extinguirse". Señaló que próximamente el ideal se cumpliría cuando los hombres comprendan que la base de la felicidad es la solidaridad entre iguales. El texto de la postal es sombrío, pero con un atisbo de esperanza que intenta impulsar el apoyo de las masas para que ejerzan presión para acelerar el proceso de liberación de Ricardo Flores Magón (véase imagen 1).

En contraparte, la presión para mantener cautivo a Flores Magón también se presentó desde la esfera gubernamental. El 27 de mayo de 1922, el procurador general Daugherty escribió una carta dirigida al abogado Weinberger, le aclaró que había discutido el caso directamente con el presidente Harding, y decidieron definitivamente que no podrían liberar a Flores Magón debido a su negativa de firmar una carta de arrepentimiento por sus actos y declaraciones: "y que los dos estábamos de acuerdo en que no deberían 

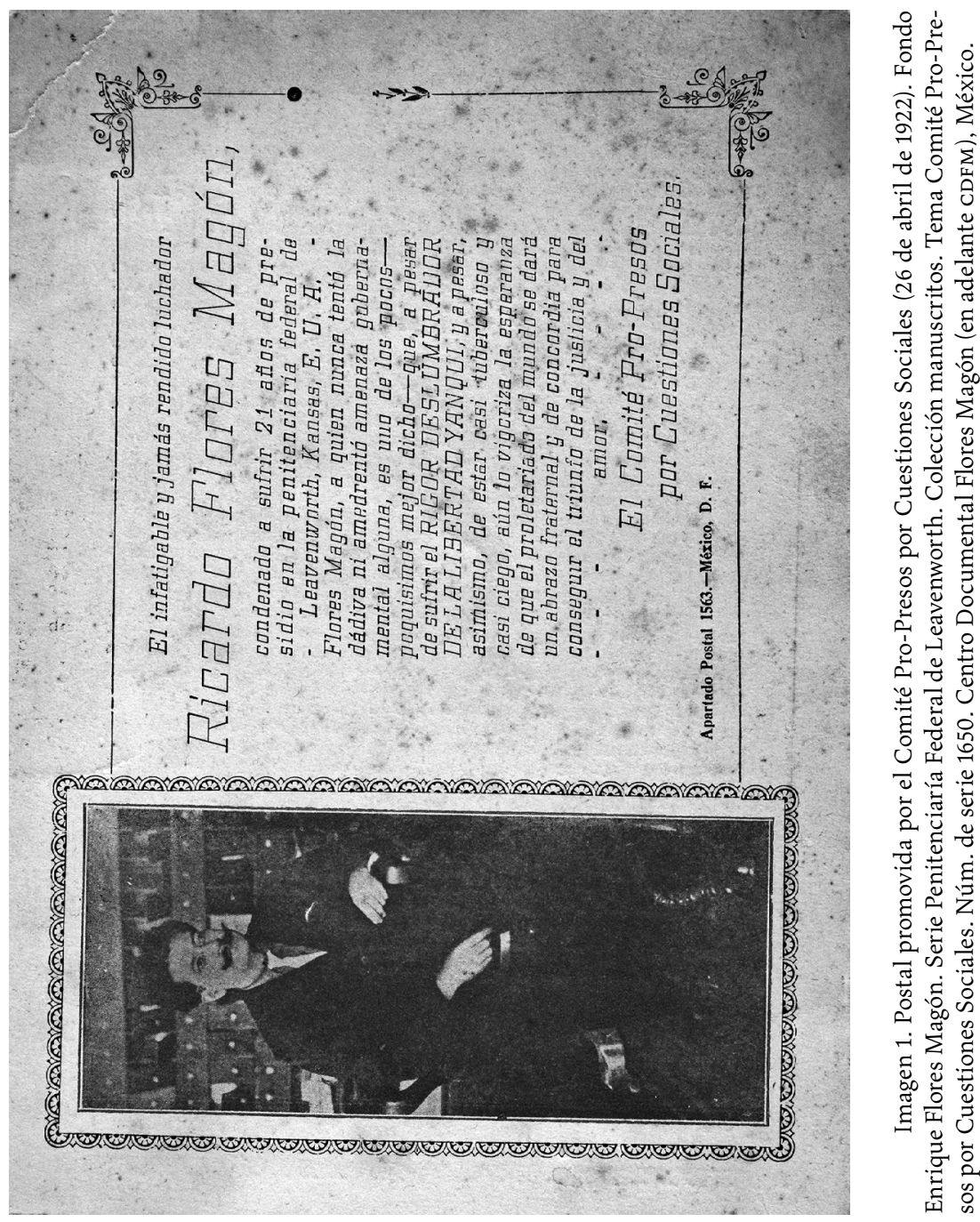
adoptarse medidas dirigidas a la concesión de indulto". ${ }^{23}$ Con esto, Ricardo Flores Magón asumió que su destino era la cárcel... de la que saldría sólo muerto:

La máquina del gobierno nunca pondrá atención a mis sufrimientos. Los intereses humanos nada tienen que hacer con los oficiales del gobierno; ellos forman parte de una tremenda máquina, sin corazón, sin nervios y sin conciencia [...] Si tuviera yo un amigo con influencia en la política, se me podría poner libre aun en el caso de que pisoteara uno o todos los diez mandamientos. Pero no tengo ninguno, y por cuestión de conveniencia debo podrirme, $y$ morir encerrado [...] ¿Asesino? No, no fue asesinato. La vida humana es cosa barata a los ojos de la máquina [...] ¿Estafa? ¡No! Si este fuera el caso ya habría sido nombrado presidente de cualquier gran corporación. Soy un soñador: este es mi crimen. ${ }^{24}$

Asimismo, desde la perspectiva binacional, en julio de 1922 el ayudante del comisionado de Comercio en la oficina del representante comercial de Estados Unidos en la ciudad de México, el señor John P. Bushnell, esribió un reporte "secreto" dirigido al entonces procurador general de Justicia Harry Daugherty. La presión que recibió Daugherty desde México influyó decisivamente para frenar la petición de libertad y deportación de Ricardo Flores Magón. El reporte de Bushnell dice lo siguiente:

Las condiciones económicas en México han venido empeorando constantemente durante los dos últimos meses, con la circunstancia muy significativa de que existe un estado de agitación que en cierto modo se encuentra alimentado por las recientes demostraciones bolshevikis [...] Tanto la Embaja$\mathrm{da}$, como el Consulado General, han estado informando con mucho empeño sobre la significación que tiene el movimiento rojo en México, y Mr. Dawson me ha mostrado su reciente informe confidencial dirigido al Departamento de Estado [...] No puedo menos que expresar a usted confidencialmente mi acuerdo personal con la opinión de Mr. Dawson. Los recientes discursos de

${ }^{23}$ Mexican Political Prisoner Held Despite Bad Health because of Unrepentance. The New York Call, 22 de noviembre de 1922. CDFM, México.

${ }^{24}$ Ricardo Flores Magón, Apóstol de la Revolución Mexicana. La Protesta, s. f. cDFM, México. 
Mr. Hoover acerca de Rusia, han sido también recibidos por la prensa americana, que confío que si el pueblo americano supiera la gran analogía que existe entre Rusia y México, se sentirían igualmente impresionado [...] No puedo menos que sentir muy profundamente los peligros de la lenta e insidiosa influencia bolsheviki que se está extendiendo por todo México y tengo la seguridad de que si el Gobierno de los Estados Unidos asume a este respecto una actitud de complacencia, pronto tendrá a sus puertas otra Rusia. ${ }^{25}$

Este reporte evidenció que los representantes gubernamentales de Estados Unidos, que se encontraban asentados en México, desconfiaban del gobierno de Obregón porque lo consideraban complaciente y de los movimientos obreros y radicales en México que encontraban espacios legales para manifestar sus ideas. El hecho de permitir la salida de Flores Magón de la penitenciaría de Leavenworth y deportarlo a México, significaba que a su llegada Ricardo pudiera reorganizar la revolución social. El reporte de Bushnell se relaciona con la contestación que días después escribió el procurador Daugtherty al abogado de Ricardo Flores Magón, el señor Weinberger:

Contestando a su carta del 8 de julio de 1922, pidiendo la libertad inmediata de Ricardo Flores Magón y de Librado Rivera, prisioneros federales en Leavenworth, con la condición de que abandonen el país, informo a usted que, según los informes recibidos, estos hombres son anarquistas peligrosos, que durante toda su vida han venido luchando continuamente contra la ley, el orden y el gobierno [...] sería sumamente imprudente dejarles regresar a México, a causa de la situación que allí prevalece y, además, que aún deportados podrían fácilmente volver a los Estados Unidos y que indudablemente así lo harían. ${ }^{26}$

El reporte de Bushnell, impregnado de este discurso obsesivo sobre la influencia bolchevique en América, fue en gran medida determinante y coronó las razones por la que se denegó a Ricardo la libertad. Las autoridades estadunidenses veían en él una amenaza potencial, lo consideraron un agi-

${ }^{25}$ Flores Magón, víctima de un complot. El Mundo, 30 de noviembre de 1922. CDFM, México.

${ }^{26}$ Flores Magón, víctima de un complot. El Mundo, 30 de noviembre de 1922. CDFM, México. 
tador que podría volver a encender la mecha de la rebelión entre los obreros radicales. Era un crítico que incomodaba tanto a la clase política de México como a la de Estados Unidos. A pesar de la negativa por parte del procurador estadunidense, en México se realizaron las que serían las últimas muestras de apoyo a favor de la liberación de Flores Magón y Rivera, justo trece días antes de la muerte de Ricardo. El 9 de noviembre de 1922 se llevó a cabo una serie de demostraciones de apoyo a estos prisioneros en Veracruz y Yucatán. El tono de las manifestaciones era enérgico y antiimperialista. Las protestas estaban conducidas, al igual que durante el funeral de Flores Magón, por grandes concentraciones populares representadas por organizaciones sindicales. Excélsior informó lo sucedido. La nota describió que los manifestantes realizaron un paro de labores. ${ }^{27}$

Según resalta la nota, la manifestación de "más de cinco mil personas", se dirigiría al consulado americano para entregar al cónsul el "pliego de la protesta", luego pondrían un cablegrama al presidente Harding anunciándole el motivo de la manifestación y un telegrama al presidente Obregón y al encargado mexicano de Negocios en Washington Manuel C. Téllez, para que interviniera en las negociaciones de liberación de Flores Magón y Rivera. El paro de labores para realizar esta manifestación se originó por la petición que hicieron los trabajadores de Progreso, Yucatán, quienes como sus homólogos de Veracruz, realizaron acciones de protesta y suspendieron durante seis horas sus labores: "Se paralizaron todos los trenes en los lugares donde se encontraban, por media hora, lanzando pitazos cada cinco minutos [...] por veinticuatro horas celebrará la Federación Obrera un mitin [...] las Ligas de resistencia protestarán ante el presidente Harding por la prisión de los mencionados líderes. Los obreros de Progreso han publicado un enérgico manifiesto."28

La nota explicó que si era necesario se haría "hasta el boycoteo de los buques americanos que vengan a puertos de México", para presionar, anunció que las protestas continuarían hasta conseguir la libertad de los prisioneros. Por su parte, el periódico El Heraldo de México con el encabezado "5 000 Mexicanos a favor de Flores Magón" reportó una "Manifestación Monstro (sic)" con "discursos de color rojo" en el puerto de Veracruz donde partici-

\footnotetext{
${ }^{27}$ Curiosa manifestación en la ciudad de las huelgas. Excélsior, 11 de septiembre de 1922. CDFM, México.

${ }^{28}$ Curiosa manifestación en la ciudad de las huelgas. Excélsior, 11 de septiembre 1 de 1922. CDFM, México.
} 
paron 5000 trabajadores "habiendo recorrido en procesión las principales calles de la ciudad" de Veracruz. Los discursos antiimperialistas se hicieron presentes en la demostración, así como el reconocimiento de Flores Magón y Rivera "a quienes llamaron mártires de la causa del proletariado". ${ }^{29}$

El 19 de noviembre de 1922, diez días después de las manifestaciones obreras, y dos días antes de su muerte, Ricardo escribió su última carta dirigida a Nicolás T. Bernal, entrañable amigo al final de su vida. En ella agradeció las muestras de cariño de los trabajadores y recalcó la solidaridad que deberían mostrar entre las diferentes agrupaciones obreras. Con palabras esperanzadoras, Ricardo continuó su carta mencionando que encontraba mucho regocijo en ver sindicatos y agrupaciones que estaban distanciadas, manifestándose en unión por su causa.

Esta sería la última carta de Flores Magón. Tres días después se anunció la muerte de Ricardo Flores Magón a través de la prensa nacional y extranjera de distintas corrientes políticas. La noticia se difundió con amplitud, y causó conmoción entre los militantes obreros. Los ánimos una vez más se encresparon y los discursos antiimperialistas y contra el gobierno estadunidense fueron inmediatos a través de la publicación de notas, discursos y manifestaciones frente a la Casa Blanca.

\section{LA MUERTE DE UN ANARQUISTA}

La madrugada del 21 de noviembre de 1922 se notificó oficialmente la muerte de Ricardo Flores Magón en la penitenciaría de Leavenworth. ${ }^{30}$ Este acontecimiento creó una crisis pública entre varios actores, entre ellos Enrique Flores

${ }^{29} 500$ mexicanos en favor de Flores Magón. El Heraldo de México, 10 de noviembre de 1922. CDFM, México.

${ }^{30}$ En una carta escrita por Ricardo Flores Magón, dirigida a su compañero anarquista Gus Teltsch el 25 de marzo de 1920, Ricardo lamentó el fallecimiento de Juan Creaghe (un médico irlandés anarquista, pedagogo y periodista, con actuación en Argentina). En la carta describió la muerte de Creaghe, pareciera que Ricardo hace una autodescripción de su fallecimiento. Da su visión que tiene sobre la muerte y su representación: "Los últimos años de este luchador por libertad fueron de tal naturaleza que hacen a uno estremecerse. Él, que amó a la humanidad, fue blanco de todos los tratamientos inhumanos. Él, que soñó la libertad, fue privado de todos los privilegios humanos. Él, que luchó para que cada criatura humana pudiera tener un hogar, no tenía un albergue propio. ¡El pobre viejo veterano de la lucha de clases! Ahora está libre y descansa. La muerte es la gran libertadora”. Recuperado de http:// archivomagon.net/obras-completas/correspondencia-1899-1922/c-1920/cor05-2 
Magón, María Talavera Brousse, las agrupaciones obreras, los grupos propresos políticos y los gobiernos de México y Estados Unidos. El fallecimiento de Flores Magón se caracteriza por ser una muerte "dramática", que se entiende como un sacrificio hacia la lucha obrera y la causa del proletariado.

Existen tres versiones del fallecimiento de Ricardo. La primera de ellas es la oficial, proveniente de la penitenciaría de Leavenworth: muerte natural a consecuencia de un paro cardiaco; la segunda señala un asesinato, versión que sostuvieron Enrique Flores Magón y Librado Rivera, este último dijo haber visto el cadáver con marcas de estrangulamiento, y acusó a los guardias del penal de perpetrar el acto.

La tercera versión es la tesis más fuerte ya que combina las dos primeras percepciones como metáfora. Se dice que Flores Magón murió "asesinado" por la justicia estadunidense. Es decir, las condiciones de salud en las que se encontraba, y que jamás consideró la autoridad como atenuante para liberarlo. Al igual que durante el proceso en que se intentó liberar a Ricardo, los discursos de la muerte de Flores Magón giraron en dos direcciones: el rechazo al gobierno estadunidense y al imperialismo.

Además, la figura de Ricardo Flores Magón después de su muerte la construyeron discursivamente sus simpatizantes y lo representaron como a un apóstol, un mártir o un maestro. En los discursos se encuentran elementos hagiográficos, que revelaban una clara influencia cívica-sagrada en cómo se esbozó la figura de Flores Magón. Se le atribuían méritos excepcionales diferentes del resto de los hombres de su época. Es decir, la figura de Ricardo Flores Magón se edificó con elementos sacros desde el punto de vista cívico, que lo proyectaron como un héroe popular para los trabajadores simpatizantes en ambos países.

La noticia de la muerte rápidamente se difundió en la prensa izquierdista y oficial en Estados Unidos y México. Los encabezados rebelaron duelo, conmoción y reclamos a la justicia estadunidense. La mayoría de las protestas se dirigieron especialmente al procurador general Hary M. Daugherty y al presidente de Estados Unidos Warren Gamaliel Harding. A ambos se les acusó, a través de telegramas, de conspiración contra Flores Magón; ellos evitaron que saliera de prisión para que lo atendieran de sus enfermedades, así "provocaron" su muerte de forma cautelosa. En general, la muerte de Flores Magón causó movilizaciones de trabajadores en México y Estados Unidos, y reactivó las protestas a favor de los presos políticos en casos similares a los de Ricardo. 
En un cartón político publicado en el periódico estadunidense The New York Call el 23 de noviembre de 1922, se representa al procurador general Hary M. Daugherty y a la muerte dándose un apretón de manos sobre el cadáver de Ricardo Flores Magón. Esto significaba el cierre de la alianza entre ambas partes. El contexto de la ilustración es el interior de la penitenciaría de Leavenworth y se observa una nota debajo del cuerpo de Flores Magón en la que se describe que fue un prisionero político muerto en la cárcel tras cumplir cinco de una sentencia de 20 años. La imagen en su conjunto representa el pensamiento generalizado dentro de los círculos obreros durante su muerte y los funerales de Flores Magón en 1923 (véase imagen 2).

La American Civil Liberties Union (ACLU), fundada en 1920 por Crystal Eastman, Roger Baldwin y Walter Nelles, organizó una protesta contra el presidente Harding por el fallecimiento de Ricardo Flores Magón. La ACLU envió al presidente Harding una carta, fechada el 22 de noviembre de 1922, escrita por su presidente, el reverendo Harry F. Ward y el director Roger N. Baldwin, defensores de los derechos civiles. En la carta señalan que la mala salud de Flores Magón era conocida desde años, y que de no haber sido negativa su atención médica o deportación, seguramente Ricardo seguiría con vida. ${ }^{31}$ La carta argumentó también que era una oportunidad para resolver los casos de los presos políticos enfermos en las diferentes cárceles del país. Incitó al presidente Harding a no repetir el mismo error que tuvo en el caso de Flores Magón. En Estados Unidos la muerte de Ricardo fue una coyuntura para comenzar a presionar al gobierno para que considerara cientos de casos de prisioneros políticos que aún se encontraban detenidos en diversas cárceles.

En un extenso reportaje presentado en el New York Call, del 22 de noviembre de 1922, se incluyó el texto de Charles W. Ervin, ${ }^{32}$ quien escribió un breve relato sobre el "asesinato" de Ricardo Flores Magón, escrito con un lenguaje de connotaciones sagradas. Ervin convocó a seguir luchando por los presos políticos que continúan encarcelados, culpó al procurador Daugherty y lo tachó de verdugo de Flores Magón, haciendo una comparación con Tomás de Torquemada, inquisidor durante el siglo xv, y con Poncio Pilatos:

\footnotetext{
${ }^{31}$ Charles W. Ervin. MAGON, DENIED FREEDOM BY DAUGHERTY, DIES IN LEAVENWORTH After long Illness. The New York Call, 22 de noviembre de 1922. CDFM, México.

32 Abogado penalista que se opuso a la primera guerra mundial.
} 


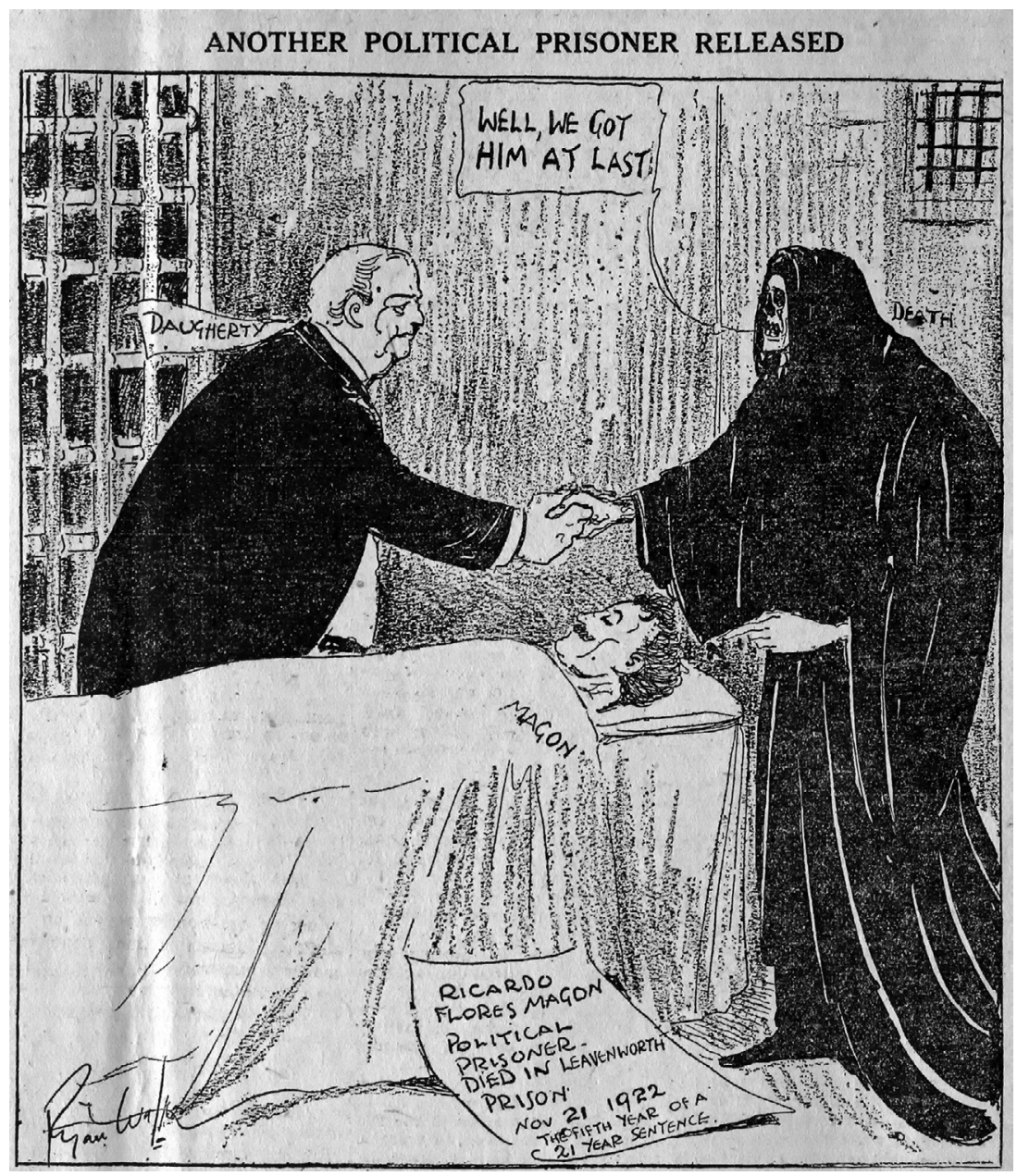

Imagen 2. [Cartón político de Fran Walt] (23 de noviembre de 1922). "MAN's DEAD; тнAт's All; Lots die", The New York Call (Nueva York). CDFM, México.

Magón fue asesinado por el hombre que era su verdadero carcelero, como si Daugherty hubiera estado presente en la cámara de tortura y con sus propias manos hubiera aplicado todos los instrumentos horribles de la época de Torquemada. Las manos de Daugherty están más profundamente teñidas con la sangre de esta noble mártir de la libertad que las manos de Poncio Pilatos 
con la sangre del carpintero judío. La grandeza del Nazareno, al menos trajo un tributo de los labios del gobernador romano, mientras que todo lo que hizo el barrigón [refiriéndose a la complexión física de Daugherty] [...] fue que las puertas de la cárcel no se abrieran a esta noble alma porque no estaba "arrepentido". 33

Por su parte, el abogado de Flores Magón, el señor Weinberger, escribió una breve carta al procurador Daugherty, en la que le cuestionó los reportes médicos presentados: "Recibí un telegrama este día que decía que Ricardo Flores Magón, prisionero político, murió de una enfermedad cardiaca. Todos los reportes de los médicos de que estaba en perfecta salud parecen muy breves ahora ¿no lo cree?" 34 El abogado Weinberger se refiere a Flores Magón como una figura mundial, que colaboró decididamente en forjar la patria mexicana: "Magón ocupará un puesto prominente entre los grandes libertadores del mundo. Cualquiera que sea la libertad política y económica que disfruta en nuestros días el pueblo mexicano, se la debe a los esfuerzos de hombres infatigables como Magón." ${ }^{35}$

En distintos diarios y semanarios se publicaron obituarios o "pensamientos” en honor a Ricardo Flores Magón. La mayoría de estas reflexiones enfatizaban el mismo discurso sobre su injusto fallecimiento, sus padecimientos físicos y su gran labor como pensador y educador de los obreros.

En el periódico neoyorquino The New York Call se publicó un cartón político que muestra al presidente Harding con la llave "maestra" que decide quién es liberado y quién encarcelado. Sobre la mesa en donde se encuentra recargado Harding, se encuentra la Constitución de los Estados Unidos de América, representando la corrupción e injusticias del gobierno estadunidense. En la primer celda el letrero anuncia que todos los espías están fuera. En la segunda celda dice que los especuladores han sido todos liberados y miles no han sido procesados. Y en la tercera celda dice: todavía encarcelados por sus opiniones. Aquí se vuelve a resaltar el castigo al discurso, a la opi-

33 Charles W. Ervin. MAgon, Denied freedom by DAUgherty, DiEs IN LEAVENWorth After long Illness. The New York Call, 22 de noviembre de 1922. CDFM, México.

${ }^{34}$ Charles W. Ervin. MAgon, DENIED FREEDOM BY DAUGHERTy, DIES IN LEAVENWORTH After long Illness. The New York Call, 22 de noviembre de 1922. CDFM, México.

35 Se lamenta el fallecimiento de R. F. Magón. Excélsior, 22 de noviembre de 1922. CDFM, México. 
nión, y no al comportamiento o acción. La caricatura demanda la libertad de todos los prisioneros encarcelados por opiniones de guerra (véase imagen 3).

En la ciudad de México también la noticia tuvo reacciones y movilizaciones en torno a Flores Magón. El periódico El Heraldo de México reportó la noticia y anunció que el suceso había "caído como bomba entre los elementos radicales de esta ciudad", y que se realizarían manifestaciones en honor a Ricardo:

la muerte de Flores Magón ocurre precisamente en los momentos en que se estaba haciendo activas gestiones para pedir su libertad. Se tenía dispuesta una manifestación de protesta en ese sentido, preparando un memorial para el Presidente Harding y ahora se llevará a cabo, pero con carácter de condolencia por la muerte del líder rojo y de protesta contra las autoridades americanas [...] se pronunciarán discursos candentes, haciéndoseles el cargo a las autoridades de los Estados Unidos, de que son las responsables de la muerte de Flores Magón, por los inhumanos tratamientos a que lo sujetaron, considerándosele como un apóstol y un mártir. ${ }^{36}$

En los periódicos oficialistas, o contrarios a la figura de Ricardo, también se informó, aunque en forma breve, el fallecimiento con otros matices discursivos. "Fuera de estas opiniones vertidas dentro del limitado círculo del socialismo americano, la muerte de Flores Magón no ha despertado nin-

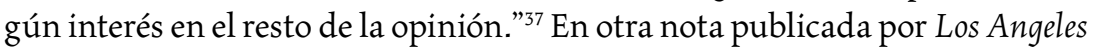
Times se informó que "Ricardo Orleans Magon [sic] nombrado a sí mismo anarquista comunista y anteriormente un agitador radical, murió ayer de enfermedades cardiacas". ${ }^{38}$

Durante este tiempo se presentaron varias opciones para resolver el entierro. Se manejaban versiones que indicaban que transportarían a Ricardo a la ciudad de México o lo sepultarían en Los Ángeles, California. Los más de 40 días que el cuerpo de Ricardo Flores Magón permaneció en Los Ángeles tuvieron una repercusión binacional entre los gobiernos y los sindicatos

${ }^{36}$ Ricardo Flores Magón muere en la penitenciaría. El Heraldo de México, 24 de noviembre de 1922. CDFM, México.

${ }^{37}$ Se lamenta el fallecimiento de R. F. Magón. Excélsior, 22 de noviembre de 1922. CDFM, México.

${ }^{38}$ Local Radical Dies In Prision. Los Angeles Times, 22 de noviembre de 1922. CDFM, México. 


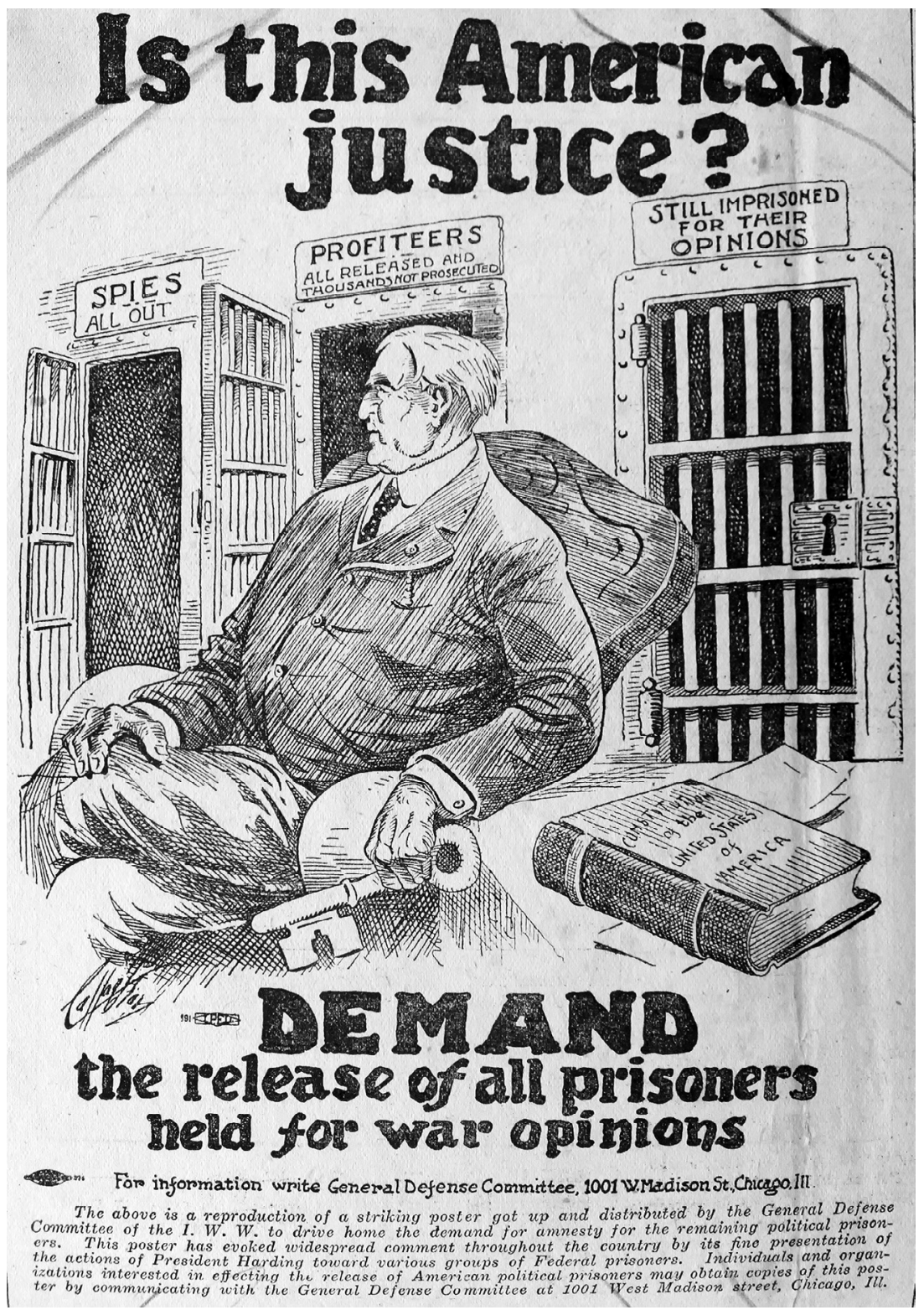

Imagen 3. MAgON'S FRIEND writes. The New York Call, 23 de noviembre de 1922. CDFM, México. 
obreros de México y Estados Unidos. Existía un clima de indecisión respecto al traslado del cuerpo de Ricardo Flores Magón, principalmente entre su hermano Enrique y su esposa María, quienes llevaban años sin hablarse debido a la ruptura entre los hermanos en 1918, antes de que fuera condenado Ricardo a 20 años de prisión. ${ }^{39}$ Asimismo, el sector obrero radical de ambos países y líderes de izquierda estadunidense querían ser parte del cortejo y la organización de la honra fúnebre. El cuerpo embalsamado de Ricardo Flores Magón permanecería en un estado liminal que cubría de incertidumbre la resolución de su funeral realizado en 1923. Finalmente, la Alianza Ferrocarrilera de México fue la encargada de realizar su traslado de la frontera norte hasta la ciudad de México para ser enterrado en el Panteón Francés.

\section{LISTA DE REFERENCIAS}

Barrera, J. (2001). Obra completa 2. Correspondencia II (1919-1922). México: ConAculta.

Bartra, A. (1991). Regeneración 1900-1918. La corriente más radical de la revolución mexicana de 1910 a través de su periódico de combate. México: ERA.

Barragan, Y. y Bray, M. (2014). Ricardo Flores Magón and the Anarchist Movement in Southern California. Recuperado de http://www.kcet.org/shows/live_at_the_ford/ flores-magon/blog-3/the-story-of-ricardo-flores-magon.html

Hernández, S. (1994). El Magonismo: Historia de una pasión libertaria 1900/1922. México: ERA.

Lomnitz, C. (2016). El regreso del camarada Ricardo Flores Magón. México: ERA.

Raat, W. D. (1988). Los revoltosos. Rebeldes mexicanos en los Estados Unidos 1903-1923. México: Fondo de Cultura Económica.

Romero, F. J. (2008). La gran ilusión. En torno al mito y a la paradoja de la revolución bolchevique en Europa. España: Universidad de La Rioja.

${ }^{39}$ Claudio Lomnitz (2016) intenta hacer una suposición histórica, a manera de reconstrucción, que ofrece una interpretación sobre el tema (pp. 609-619). 


\section{OTRAS FUENTES}

Archivos

CDFM Centro Documental Flores Magón, El Hijo del Ahuizote, México.

Archivo electrónico Ricardo Flores Magón, DEH-INAH, México.

Bibliografía

Hart, J. (1980). El anarquismo y la clase obrera mexicana 1860-1931. México: Siglo XXI Editores. 